\title{
The best therapeutic option for oral treatment of secondary anaemia in chronic kidney disease: role of Ferric Sodium EDTA, in association with Vitamin C, Folic acid, Copper gluconate, Zinc Gluconate and Selenomethionine
}

\author{
Luca Di Lullo ${ }^{1}$, Nicola Marchitto ${ }^{2 *}$, Annalisa Curcio ${ }^{3}$, Adriana Romano ${ }^{4}$, Lucia Laura Bilo ${ }^{5}$, Michele Pironti ${ }^{3}$ and Gianfranco Raimondi ${ }^{6}$
}

${ }^{1}$ Department of Nephrology and Dialysis, "L. Parodi-Delfino" Hospital, Rome, Italy

${ }^{2}$ Department of Internal Medicine, Alfredo Fiorini Hospital, Terracina (Latina), Italy

${ }^{3}$ Medical Department, Aqma Italia S.p.A., Milan, Italy

${ }^{4}$ Medical Department, Merqurio Pharma S.r.l., Naples, Italy

${ }^{5}$ Medical Oncology Department, University "Federico II" of Naples, Italy

${ }^{6}$ Department of Medico-Surgical Sciences and Biotechnologies, Faculty of Internal Medicine, "Sapienza” University of Rome, Italy

\begin{abstract}
Introduction: Iron deficiency anaemia (IDA) represents a serious co-morbidity in patients with chronic kidney disease (CKD), that impacts patient's quality of life, physical and cognitive functions. There is a correlation between anaemia worsening and kidney function decline, showing an increased risk of progression to end-stage kidney disease (ESKD) in anaemic patients. The aim of this study is to evaluate the effect of Ferric Sodium EDTA, in combination with vitamin C, folic acid, copper gluconate, zinc gluconate and selenomethionine (Ferachel forte ${ }^{\circledR}$ ) treatment in nondialysis-dependent chronic kidney disease (NDD-CKD) elderly patients with secondary anaemia not responders to ferrous sulphate therapy, in comparison with an oral liposomal iron formulation.
\end{abstract}

Methods: We enrolled thirty patients in our Geriatric Clinic of the S. Giovanni di Dio Hospital, Fondi (Latina), Italy. All patients have been treated for 6 months with ferrous sulphate prolonged-release tablets $1 \mathrm{tab} / \mathrm{day}$, containing $105 \mathrm{mg}$ of ferrous ion (T0). After evaluation of blood parameters at T1 (after 6 months) patients were randomized to treatment with Ferric Sodium EDTA in combination with vitamin C, folic acid, copper gluconate, zinc gluconate and selenomethionine (Ferachel Forte $\left.^{\circledR}\right) 1 \mathrm{tab} /$ day, containing $30 \mathrm{mg}$ of ferric ion (Group 1; N=15), or with Ferric liposomal formulation, containing $30 \mathrm{mg}$ of ferric ion (Group 2; $\mathrm{N}=15$ ), for $6 \mathrm{months}$ (T2). Iron blood parameters of haemoglobin ( $\mathrm{Hb}$ ), sideremia, ferritin, and total transferrin saturation (Tsat) have been recorded at T0, T1 and T2.

Results: At T1 time the mean results of blood parameters evaluated in patients treated with ferrous sulphate did not show a marked improvement of anaemic disease. After shifting to different therapies (Group 1 and Group 2) for 6 months both groups of treatment reported statistically significant improvements of iron blood parameters of $\mathrm{Hb}$, sideremia, ferritin and Tsat. The results obtained allow us to confirm the real superiority of the oral administration of Ferric Sodium EDTA, in combination with vitamin C, folic acid, copper gluconate, zinc gluconate and selenomethionine (Ferachel forte ${ }^{\circledR}$ ) in improving blood parameters of Hb, sideremia, ferritin and Tsat, in comparison to the other formulations used in this preliminary study.

Conclusions: This study confirmed the efficacy and the safety of Ferric Sodium EDTA, in combination with vitamin C, folic acid, copper gluconate, zinc gluconate and selenomethionine $\left(\right.$ Ferachel forte ${ }^{\circledR}$ ) treatment in NDD-CKD elderly patients with secondary anaemia not responders to ferrous sulphate therapy.

\section{Introduction}

Iron deficiency anaemia (IDA) represents a serious co-morbidity in patients with chronic kidney disease (CKD), that impacts patient's quality of life, physical and cognitive functions and is associated with an increased risk of adverse outcomes, including cardiovascular disease (CVD), cardiovascular hospitalization and mortality for any cause $[1,2]$.

Furtherly, there is a correlation between anaemia worsening and kidney function decline, showing an increased risk of progression to end-stage kidney disease (ESKD) in anaemic patients. In particular, in patients with nondialysis-dependent chronic kidney disease (NDD$\mathrm{CKD}$ ), lower haemoglobin ( $\mathrm{Hb}$ ) levels have been associated with higher mortality rate and major risk of ESRD [1-4].
The causes contributing to the pathogenesis of IDA in CKD patients are, first of all, the reduced renal function itself, that leads to a lower production of erythropoietin, with inadequate erythropoiesis, along with increased inflammatory cytokines. At the same time

${ }^{\star}$ Correspondence to: Nicola Marchitto, Specialist in Geriatrics and Gerontology, San Giovannni di Dio Hospital, Department of Internal Medicine, 1, San Magno street, Fondi, Latina, 04022, Italy, Tel: +393277064979; E-mail: n.marchitto@ ausl.latina.it

Key words: iron deficiency anaemia, ferric sodium EDTA, chronic kidney disease, elderly.

Received: April 09, 2021; Accepted: April 19, 2021; Published: April 22, 2021 
Luca Di Lullo (2021) The best therapeutic option for oral treatment of secondary anaemia in chronic kidney disease: role of Ferric Sodium EDTA, in association with Vitamin C, Folic acid, Copper gluconate, Zinc Gluconate and Selenomethionine

poor absorption of iron from diet and inability to use its deposits are common in CKD patients. Inflammatory status of CKD patients strongly influences hepcidin levels, that in turn are crucial for iron availability in the organism. In addition, CKD patients are affected by increased gastrointestinal (GI) blood loss and shortened erythrocyte lifespan [1-19].

Since it is recognised that CKD patients develop anaemia in the early stages of renal disease the opportunity for earlier intervention and a more effective management, can lead to better outcomes and minor risk of disease worsening [1,20-23].

Iron supplementation is recommended for CKD patients with anaemia. Recently updated guidelines states that oral iron supplementation is recommended in NDD-CKD patients not on erythropoiesis-stimulating agent (ESA) therapy, with switch to intravenous (IV) iron therapy in case of intolerance to oral treatment, and/or inadequate $\mathrm{Hb}$ target after 3 months of therapy [6,7].

Poor tolerance to oral iron treatment is mainly due to GI side effects, related to low bioavailability of traditional oral iron formulation, like ferrous sulphate. In this case GI adverse events (AEs) are related to the high percentage of not adsorbed iron (about 90-85\%) [6,7].

Actually, new oral iron formulations, can warranty a similar or superior iron blood level respect the IV iron supplementation without procedural risk due to IV treatment or saline supplementation [8-11]. Recent studies underlined that the use of a new oral iron formulation based on Ferric Sodium EDTA, in combination with vitamin C, folic acid, copper gluconate, zinc gluconate and selenomethionine $\left(\right.$ Ferachel forte ${ }^{\star}$ ) is resulted safe and effective for IDA treatment in elderly patients with low-moderate kidney failure [8-11]. In particular, cardiovascular safety of this oral intervention has been confirmed by Heart Rate Variability (HRV) analysis. HRV analysis is able to explore the neurovegetative system, and it has been observed that the increase in total HRV is associated with survival, while the progressive decreases of HRV have been associated with deterioration and death. Alterations of the spectral analysis are present in case of comparison between oral and IV iron supplementation and could provide an evaluation of the prognosis and determine the effectiveness of intervention. Oral therapy with Ferric Sodium EDTA, in combination with vitamin C, folic acid, copper gluconate, zinc gluconate and selenomethionine allows to avoid adverse events due to iron IV administration that can be related to injection site, such as phlebitis and thrombophlebitis, and/or can increase the risk of allergic reactions and/or aggravate pre-existing conditions such as heart failure or renal failure [8-11].

To date, oral treatment with ferrous sulphate is still common in nephrology department due to low-cost therapy and easy accessibility, however GI AEs are frequently reported, including nausea, constipation, diarrhea, and dyspepsia. In addition, often the response to oral ferrous sulphate therapy is low and inadequate to reach iron blood parameters target [6].

The aim of this study is to evaluate the effect of Ferric Sodium EDTA, in combination with vitamin $\mathrm{C}$, folic acid, copper gluconate, zinc gluconate and selenomethionine (Ferachel forte ${ }^{\circ}$ ) treatment in NDD-CKD elderly patients with secondary anaemia not responders to ferrous sulphate therapy, in comparison with an oral liposomal iron formulation.

\section{Materials and Methods}

In this preliminary analysis we enrolled 30 elderly patients (16 men and 14 women) in our Geriatric Clinic of the S. Giovanni di Dio
Hospital, Fondi (Latina), Italy. All enrolled patients were elderly (68.4 \pm 1.724 years old) with a recent diagnosis of secondary anaemia due to iron deficiency and moderate CKD (eGFR $45.533 \pm 2.295 \mathrm{ml} / \mathrm{min} / 1.73$ $\mathrm{m}^{2}$ ). All patients have been treated for 6 months with ferrous sulphate prolonged-release tablets $1 \mathrm{tab} /$ day, containing $105 \mathrm{mg}$ of ferrous ion.

The study design reported in Figure 1 provides a detailed description of the subdivision of the 30 enrolled subjects. Briefly, patients have been treated for 6 months with ferrous sulphate prolonged-release tablets $1 \mathrm{tab} /$ day, containing $105 \mathrm{mg}$ of ferrous ion (T0). After evaluation of blood parameters at T1 (after 6 months) patients were randomized to treatment with Ferric Sodium EDTA in combination with vitamin C, folic acid, copper gluconate, zinc gluconate and selenomethionine (Ferachel Forte $^{\oplus}$ ) 1 tab/day, containing $30 \mathrm{mg}$ of ferric ion (Group 1; $\mathrm{N}=15$ ), or with Ferric liposomal formulation, containing $30 \mathrm{mg}$ of ferric ion (Group 2; $\mathrm{N}=15$ ), for 6 months (T2, Figure 1).

All enrolled subjects underwent laboratory tests $(\mathrm{Hb}$, sideremia, ferritin, transferrin) in basal conditions (T0), after 6 months of treatment with ferrous sulphate (T1) and after 6 months of treatment with Ferric Sodium EDTA in association (Group 1) or Ferric liposomal formulation (Group 2) (T2).

This study was conducted in accordance with the Declaration of Helsinki, and the protocol respects the Ethical Committee opinion about observational study. Patients were included after providing written informed consent.

Statistical analysis was performed using Paired T-test with Sigmastat v. 3.5 (San Jose, CA, USA) analysis program for Windows $\mathrm{XP}$, by comparing all serum parameters included in the study recorded at T0, T1 and T2.

\section{Results}

After 6 months of therapy with ferrous sulphate the mean results of blood parameters evaluated in enrolled patients did not show a marked improvement of anaemic disease, often with changes that did not reach statistical significance (Tables 1 and 2). After shifting to different therapies (Group 1 and Group 2) for 6 months, we noticed an important improvement in both groups of treatment, with a real superiority of Group 1 results. In particular, $\mathrm{Hb}$ level raised from $10.247 \pm 0.673 \mathrm{~g} / \mathrm{dL}$ to $12.327 \pm 1.282 \mathrm{~g} / \mathrm{dL}\left(\mathrm{P}<0.001^{*}\right)$ in Group 1 , while the Hb level raised from $10.347 \pm 0.781 \mathrm{~g} / \mathrm{dL}$ to $11.060 \pm 1.218 \mathrm{~g} /$ $\mathrm{dL}\left(\mathrm{P}<0.011^{\star}\right)$ in Group 2 (Tables 1 and 2).

Similar statistically significant improvements were obtained in Group 1 patients for sideremia levels increased from $35.267 \pm 13,451$ $\mathrm{mcg} / \mathrm{dL}$ to $63.000 \pm 12.694 \mathrm{mcg} / \mathrm{dL}\left(\mathrm{P}<0.001^{*}\right)$, ferritin reduced from $246.867 \pm 57.686 \mathrm{mcg} / \mathrm{dL}$ to $191.200 \pm 29.042 \mathrm{mcg} / \mathrm{dL}\left(\mathrm{P}<0.013^{\star}\right)$ and total transferrin saturation (Tsat) raised from $16.253 \pm 2.844$ to 25.133 $\pm 2.855\left(\mathrm{P}<0.001^{\star}\right)$. Corresponding results for Group 2 patients were increase of sideremia levels from $30.667 \pm 8.321 \mathrm{mcg} / \mathrm{dL}$ to $40.067 \pm$

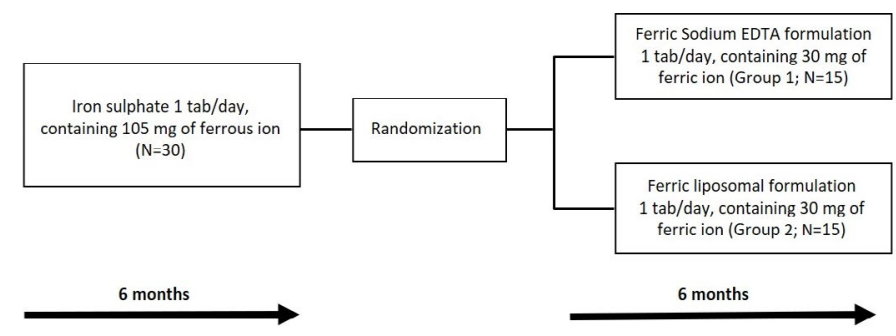

Figure 1. Study Design 
Luca Di Lullo (2021) The best therapeutic option for oral treatment of secondary anaemia in chronic kidney disease: role of Ferric Sodium EDTA, in association with Vitamin C, Folic acid, Copper gluconate, Zinc Gluconate and Selenomethionine

Table 1. Iron blood parameters in Group 1 patients, after administration of ferrous sulphate for 6 months (T0-T1) and after administration of Ferric Sodium EDTA in association for 6 months (T1-T2). Data are expressed as mean \pm standard deviation

\begin{tabular}{|l|l|l|l|}
\hline & Ferrous sulphate (T0) & Ferrous sulphate (T1) & Probability (P $<\mathbf{0 . 0 5 0 )}$ \\
\hline $\mathrm{Hb}(\mathrm{g} / \mathrm{dL})$ & $9.693 \pm 1.071$ & $10.247 \pm 0.673$ & $0.047^{*}$ \\
\hline $\mathrm{Fe}^{2+}(\mathrm{mcg} / \mathrm{dL})$ & $28.467 \pm 2.642$ & $35.267 \pm 13.451$ & 0.078 \\
\hline Ferritin $(\mathrm{mcg} / \mathrm{dL})$ & $222.933 \pm 67.410$ & $246.867 \pm 57.686$ & $<0.001^{*}$ \\
\hline $\mathrm{Tsat}(\%)$ & $15.307 \pm 2.393$ & $16.253 \pm 2.844$ & 0.189 \\
\hline & Ferric Sodium EDTA in association $(\mathrm{T} 1)$ & Ferric Sodium EDTA in association (T2) & Probability (P $<\mathbf{0 . 0 5 0 )}$ \\
\hline $\mathrm{Hb}(\mathrm{g} / \mathrm{dL})$ & $10.247 \pm 0.673$ & $12.327 \pm 1.282$ & $<0.001^{*}$ \\
\hline $\mathrm{Fe}^{2+}(\mathrm{mcg} / \mathrm{dL})$ & $35.267 \pm 13.451$ & $63.000 \pm 12.694$ & $<0.001^{*}$ \\
\hline Ferritin $(\mathrm{mcg} / \mathrm{dL})$ & $246.867 \pm 57.686$ & $191.200 \pm 29.042$ & $<0.013^{*}$ \\
\hline Tsat $(\%)$ & $16.253 \pm 2.844$ & $25.133 \pm 2.855$ & $<0.001^{*}$ \\
\hline
\end{tabular}

Table 2. Iron blood parameters in Group 2 patients, after administration of ferrous sulphate for 6 months (T0-T1) and after administration of Ferric liposomal formulation for 6 months (T1T2). Data are expressed as mean \pm standard deviation

\begin{tabular}{|l|l|l|l|}
\hline & Ferrous sulphate (T0) & Ferrous sulphate (T1) & Probability (P< 0.050) \\
\hline $\mathrm{Hb}(\mathrm{g} / \mathrm{dL})$ & $9.920 \pm 1.211$ & $10.347 \pm 0.781$ & $0.049^{*}$ \\
\hline $\mathrm{Fe}^{2+}(\mathrm{mcg} / \mathrm{dL})$ & $27.733 \pm 2.549$ & $30.667 \pm 8.321$ & 0.244 \\
\hline Ferritin $(\mathrm{mcg} / \mathrm{dL})$ & $270.400 \pm 98.594$ & $290.000 \pm 83.661$ & $<0.001^{*}$ \\
\hline $\mathrm{Tsat}(\%)$ & $15.840 \pm 2.659$ & $16.960 \pm 2.862$ & 0.124 \\
\hline & Ferric liposomal formulation $(\mathrm{T} 1)$ & Ferric liposomal formulation (T2) & Probability (P < 0.050) \\
\hline $\mathrm{Hb}(\mathrm{g} / \mathrm{dL})$ & $10.347 \pm 0.781$ & $11.060 \pm 1.218$ & $<0.011^{*}$ \\
\hline $\mathrm{Fe}^{2+}(\mathrm{mcg} / \mathrm{dL})$ & $30.667 \pm 8.321$ & $40.067 \pm 10.800$ & $<0.001^{*}$ \\
\hline Ferritin $(\mathrm{mcg} / \mathrm{dL})$ & $290.000 \pm 83.661$ & $257.667 \pm 36.317$ & $<0.036^{*}$ \\
\hline Tsat $(\%)$ & $16.960 \pm 2.862$ & $18.767 \pm 2.931$ \\
\hline
\end{tabular}

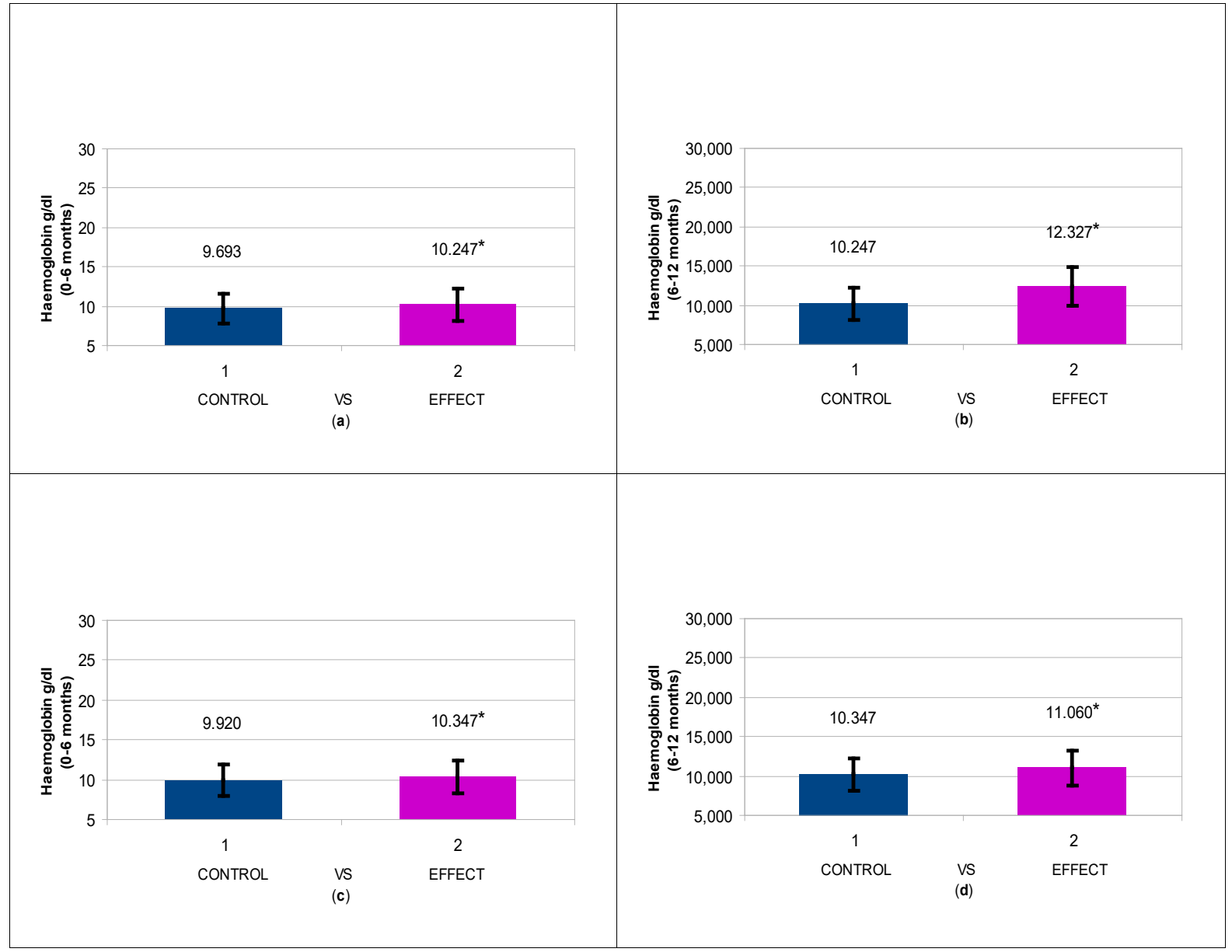

Figure 2. Descriptive Analysis of Haemoglobin variation (g/dL) in the different patient groups: a) Group 1 patients, after administration of ferrous sulphate for 6 months (T0-T1); b) Group 1 patients after administration of Ferric Sodium EDTA in association for 6 months (T1-T2); c) Group 2 patients, after administration of ferrous sulphate for 6 months (T0-T1); d) Group 2 patients after administration of Ferric liposomal formulation for 6 months (T1-T2). Data are expressed as mean + standard deviation 
Luca Di Lullo (2021) The best therapeutic option for oral treatment of secondary anaemia in chronic kidney disease: role of Ferric Sodium EDTA, in association with Vitamin C, Folic acid, Copper gluconate, Zinc Gluconate and Selenomethionine

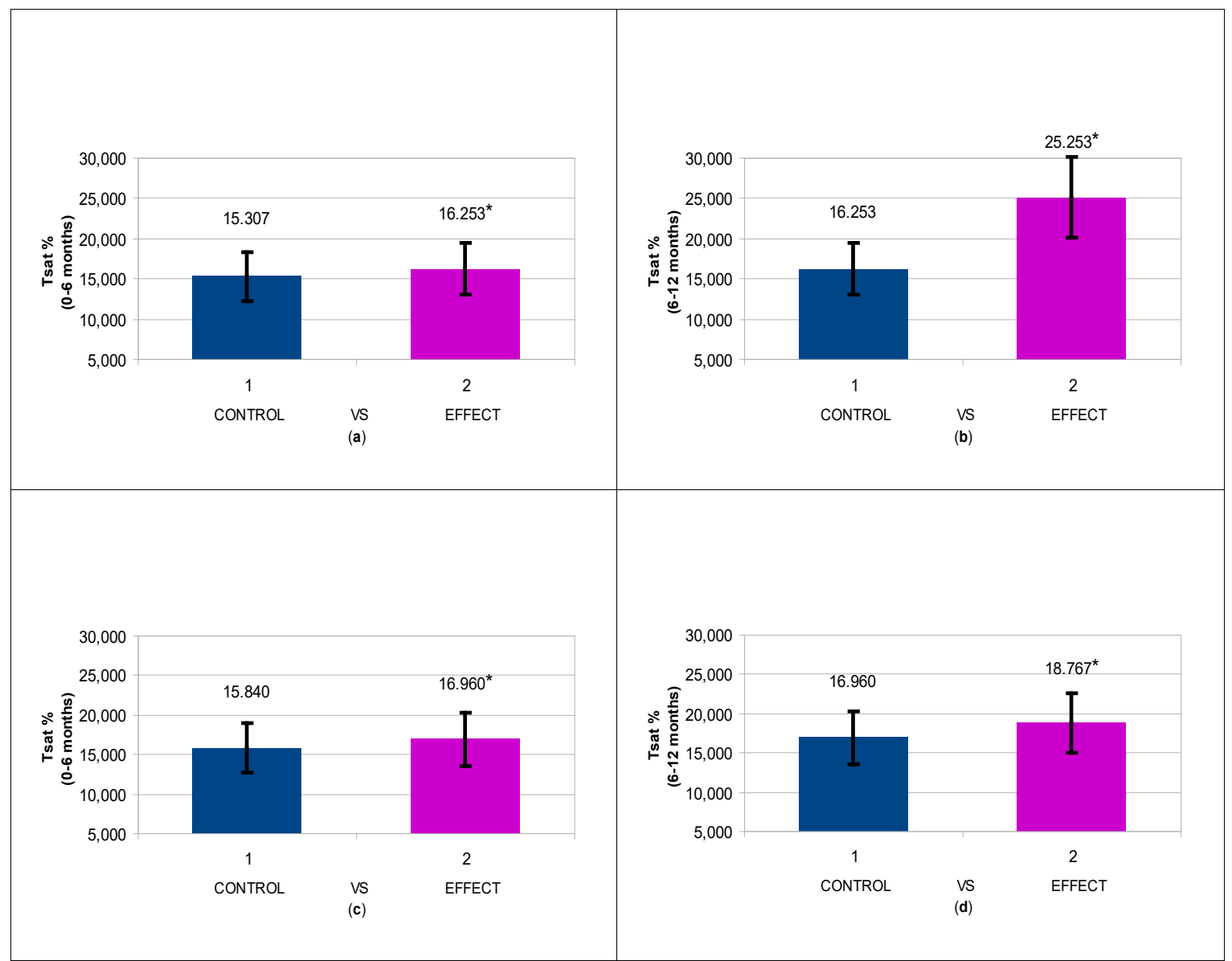

Figure 3. Descriptive Analysis of the Tsat value (\%) in the different patient groups: a) Group 1 patients, after administration of ferrous sulphate for 6 months (T0-T1); b) Group 1 patients after administration of Ferric Sodium EDTA in association for 6 months (T1-T2); c) Group 2 patients, after administration of ferrous sulphate for 6 months (T0-T1); d) Group 2 patients after administration of Ferric liposomal formulation for 6 months (T1-T2). Data are expressed as mean \pm standard deviation

$10.800 \mathrm{mcg} / \mathrm{dL}\left(\mathrm{P}<0.001^{\star}\right)$, ferritin reduction from $290.000 \pm 83.661$ $\mathrm{mcg} / \mathrm{dL}$ to $257.667 \pm 36.317 \mathrm{mcg} / \mathrm{dL}\left(\mathrm{P}<0.036^{\star}\right)$ and Tsat raised from $16.960 \pm 2.862$ to $18.767 \pm 2.931\left(\mathrm{P}<0.001^{\star}\right)$ (Tables 1 and 2$)$.

Taken together, the results regarding $\mathrm{Hb}$ and Tsat levels shown in Figures 2 and 3, respectively, confirm that the switch to Ferric Sodium EDTA combination and/or Ferric liposomal formulation allows to reach statistically significant improvements, with major entity in Group 1 patients.

These results allow us to confirm the real superiority of the oral administration of Ferric Sodium EDTA, in combination with vitamin $\mathrm{C}$, folic acid, copper gluconate, zinc gluconate and selenomethionine (Ferachel forte ${ }^{\odot}$ ) in improving blood parameters of $\mathrm{Hb}$, sideremia, ferritin and Tsat, in comparison to the other formulations used in this preliminary study.

Treatments with Ferric Sodium EDTA combination and/or Ferric liposomal formulation were safe and well tolerated, since patients did not report AEs during the whole treatment period from T1 to T2. Conversely, from $\mathrm{T} 0$ to $\mathrm{T} 1$ about $33 \%$ of patients $(\mathrm{N}=10)$ reported GI AEs, including constipation, diarrhea, nausea, abdominal cramps, and vomiting.

\section{Discussion/Conclusion}

This preliminary study originates from the observation that oral iron supplementation is recommended for NDD-CKD patients not on
ESA therapy, and that switch to IV iron therapy is required in case of intolerance to oral treatment and/or loss to reach adequate iron blood parameters [7]. Furtherly, of note, physicians should always respect European Medicines Agency (EMA) recommendations issued in order to limit the risk of allergic reactions correlated to IV iron administration, that indicates the use of oral iron supplementation as first line therapy for anaemic patients [12].

To the best of our knowledge, however, the use of IV iron therapy as first line treatment, especially for anaemic CKD patients, is very frequent. We believe that this choice is mainly due to the alternative strategies of oral treatment that are still recognised as the use of traditional oral iron formulation, still frequently administrated, for the low cost and the easily availability of therapies, but that in turn caused GI AEs and inadequate response to treatment, both caused by the poor gastrointestinal absorption of traditional formulations in market.

However, new oral formulations have overcome these limitations, thanks to the increase of iron absorption derived from new iron sources. Among these, there is Ferric Sodium EDTA already recommended by the WHO Guidelines on food fortification with micronutrients, as iron source for mass fortification of high-phytate cereal flours and for sauces with a high peptide content (e.g., fish sauce, soy sauce) [13]. Ferric sodium EDTA showed in recent studies important results of efficacy and safety in several settings, such as pregnant women, anaemic preschool and school-aged children and adolescents [14-24]. 
Luca Di Lullo (2021) The best therapeutic option for oral treatment of secondary anaemia in chronic kidney disease: role of Ferric Sodium EDTA, in association with Vitamin C, Folic acid, Copper gluconate, Zinc Gluconate and Selenomethionine

Recently several studies have confirmed the safety and efficacy of Ferric Sodium EDTA, in combination with vitamin C, folic acid, copper gluconate, zinc gluconate and selenomethionine (Ferachel forte $^{\diamond}$ ) in elderly "frailty" patients with secondary anaemia and low kidney failure [8-11]. This product has been formulated to improve iron absorption thanks to synergistic effect of active ingredients. It is for long time well known the role of vitamin C, folic acid, copper, zinc and selenium in increasing iron adsorption as well as their involvement in the improvement of anaemic patients [25-28]. We decided to use this new oral formulation because of previous results showing efficacy results comparable to IV formulation [8-11], in order to verify its use in NDD-CKD elderly patients with secondary anaemia not responders to ferrous sulphate therapy, in comparison with an oral liposomal iron formulation.

Our results confirm the efficacy and the safety of Ferric Sodium EDTA in association in the clinical setting of this study, suggesting its use in NDD-CKD patients not requiring IV iron administration. In this way it is possible to avoid and/or limiting the use of IV iron formulations with consequently reduction of the risk of report IV iron therapy-related AEs. Commonly, these events include injection site reactions, like pain, bleeding, along with phlebitis and thrombophlebitis. Furtherly, by limiting IV iron use it is possible to reduce the risk of allergic reactions and/or aggravate pre-existing conditions such as heart failure or renal failure.

This study represents a preliminary analysis with the limitation of small sample size, that cannot allow to generalize the obtained results to the overall NDD-CKD population of patients. However, it can be considered as a strong starting point to deepen the topic and to expand the use of new oral iron formulation like Ferric Sodium EDTA, in combination with vitamin $\mathrm{C}$, folic acid, copper gluconate, zinc gluconate and selenomethionine (Ferachel forte ${ }^{\star}$ ) in CKD anaemic patients. Future perspectives of our research will be to investigate the inflammatory status of this kind of patients and to evaluate if new oral iron therapies can be useful from this point of view.

In conclusion, this study confirmed the efficacy and the safety of Ferric Sodium EDTA, in combination with vitamin C, folic acid, copper gluconate, zinc gluconate and selenomethionine (Ferachel forte $^{\star}$ ) treatment in NDD-CKD elderly patients with secondary anaemia not responders to ferrous sulphate therapy. In addition, we are comfortable to affirm that the use of this new oral iron therapy can be a valid alternative to the still too much frequent use of IV iron therapies also in patients that can be managed with oral treatment.

\section{Acknowledgement}

We are particularly grateful to all the different teams for the collaboration.

\section{Conflict of Interest}

The authors have no conflicts of interest to declare.

\section{References}

1. Awan AA, Walther CP, Richardson PA, Shah M, Winkelmayer WC, et al. (2019) Prevalence, correlates and outcomes of absolute and functional iron deficiency anemia in nondialysis-dependent chronic kidney disease. Nephrol Dial Transplant 36: 129136. [Crossref]

2. McClellan W, Aronoff SL, Bolton WK, Hood S, Lorber DL, et al. (2004) The prevalence of anemia in patients with chronic kidney disease. Curr Med Res Opin 20: 1501-1510. [Crossref]

3. Gafter-Gvili A, Schechter A, Rozen-Zvi B (2019) Iron Deficiency Anemia in Chronic Kidney Disease. Acta Haematol 142: 44-50.
4. Kovesdy CP, Trivedi BK, Kalantar-Zadeh K, Anderson JE (2006) Association of anemia with outcomes in men with moderate and severe chronic kidney disease. Kidney Int 69: 560-564. [Crossref]

5. Babitt JL, Lin HY (2012) Mechanisms of anemia in CKD. J Am Soc Nephrol 23: 16311634. [Crossref]

6. Pergola PE, Fishbane S, Ganz T (2019) Novel Oral Iron Therapies for Iron Deficiency Anemia in Chronic Kidney Disease. Adv Chronic Kidney Dis 26: 272-291. [Crossref]

7. Ratcliffe LEK, Thomas W, Glen J, Padhi S, Pordes BAJ, et al. (2016) Diagnosis and Management of Iron Deficiency in CKD: A Summary of the NICE Guideline Recommendations and Their Rationale. Am J Kidney Dis 67: 548-558. [Crossref]

8. Marchitto N, Curcio A, Iannarelli N, Petrucci A, Romano A, et al. (2020) A pilot study on secondary anaemia in "frailty" patients treated with the Ferric Sodium EDTA in combination with vitamin $\mathrm{C}$, folic acid, copper gluconate, zinc gluconate and selenomethionine: safety of treatment explored by HRV non-linear analysis as predictive factor of cardiovascular tolerability. Eur Rev Med Pharmacol Sci 24: 77767783. [Crossref]

9. Marchitto N, Sindona F, Pannozzi A, Petrucci A, Fusco L, et al. (2019) Role of Ferric Sodium EDTA associated with vitamin C, folic acid, copper gluconate, zinc gluconate and selenomethionine administration in patients with secondary anaemia. Effects on hemoglobin value and cardiovascular risk. Health Sci J 13: 682.

10. Marchitto N, Petrucci A, Fusco L, Curcio A, Romano A, et al. (2019) Effect of Ferric Sodium EDTA administration, in combination with vitamin $\mathrm{C}$, folic acid, copper gluconate, zinc gluconate and selenomethionine, on cardiovascular risk evaluation: exploration of the HRV frequency domain. Clin Pract 16: 1245-1251.

11. Curcio A, Romano A, Marchitto N, Pironti M, Raimondi G (2018) Efficacy and Safety of a New Formulation of Ferric Sodium EDTA Associated with Vitamin C, Folic Acid, Copper Gluconate, Zinc Gluconate and Selenomethionine Administration in Patients with Secondary Anaemia. J Blood Lymph 8: 224-225.

12. New recommendations to manage risk of allergic reactions with intravenous ironcontaining medicines (EMA/579491/2013).

13. World Health Organization. Guidelines on food fortification with micronutrients/edited by Lindsay Allen, Bruno de Benoist, Omar Dary and Richard Hurrell.

14. Han XX, Sun YY, Ma AG, Yang F, Zhang FZ, et al. (2011) Moderate NaFeEDTA and ferrous sulfate supplementation can improve both hematologic status and oxidative stress in anemic pregnant women. Asia Pac J Clin Nutr 20: 514-520. [Crossref]

15. Van Thuy P, Berger J, Nakanishi Y, Khan NC, Lynch S, et al. (2005) The use of NaFeEDTA-fortified fish sauce is an effective tool for controlling iron deficiency in women of childbearing age in rural Vietnam. J Nutr 135: 2596-2601. [Crossref]

16. Cignini P, Mangiafico L, Padula F, D’Emidio L, Dugo N, et al. (2015) Supplementation with a dietary multicomponent (Lafergin $(\mathbb{R})$ ) based on Ferric Sodium EDTA (Ferrazone( $(\mathbb{B})$ ): results of an observational study. J Prenat Med. 9: 1-7. [Crossref]

17. Huo J, Sun J, Miao H, Yu B, Yang T, et al. (2002) Therapeutic effects of NaFeEDTAfortified soy sauce in anaemic children in China. Asia Pac J Clin Nutr 11: 123-127. [Crossref]

18. Herter-Aeberli I, Eliancy K, Rathon Y, Loechl CU, Pierre JM, et al. (2017) In Haitian women and preschool children, iron absorption from wheat flour-based meals fortified with sodium iron EDTA is higher than that from meals fortified with ferrous fumarate and is not affected by Helicobacter pylori infection in children. Br J Nutr 118: 273-279. [Crossref]

19. Muthayya S, Thankachan P, Hirve S, Amalrajan V, Thomas T, et al. (2012) Iron fortification of whole wheat flour reduces iron deficiency and iron deficiency anemia and increases body iron stores in Indian school-aged children. J Nutr 142: 1997-2003. [Crossref]

20. Longfils P, Monchy D, Weinheimer H, Chavasit V, Nakanishi Y, et al. (2008) A comparative intervention trial on fish sauce fortified with NaFe-EDTA and FeSO4 \pm citrate in iron deficiency anemic school children in Kampot, Cambodia. Asia Pac J Clin Nutr 17: 250-257. [Crossref]

21. Teshome EM, Otieno W, Terwel SR, Osoti V, Demir AY, et al. (2017) Comparison of home fortification with two iron formulations among Kenyan children: Rationale and design of a placebo-controlled non-inferiority trial. Contemp Clin Trials Commun 7: 1-10. [Crossref]

22. Huo JS, Yin JY, Sun J, Huang J, Lu ZX, et al. (2015) Effect of NaFeEDTA-Fortified Soy Sauce on Anemia Prevalence in China: A Systematic Review and Meta-analysis of Randomized Controlled Trials. Biomed Environ Sci 28: 788-798. [Crossref]

23. De-Regil LM, Jefferds MED, Peña-Rosas JP (2017) Point-of-use fortification of foods with micronutrient powders containing iron in children of preschool and school-age. Cochrane Database Syst Rev 11: CD009666. [Crossref] 
Luca Di Lullo (2021) The best therapeutic option for oral treatment of secondary anaemia in chronic kidney disease: role of Ferric Sodium EDTA, in association with Vitamin C, Folic acid, Copper gluconate, Zinc Gluconate and Selenomethionine

24. Wang B, Zhan S, Xia Y, Lee L (2008) Effect of sodium iron ethylenediaminetetraacetate (NaFeEDTA) on haemoglobin and serum ferritin in iron-deficient populations: a systematic review and meta-analysis of randomised and quasi-randomised controlled trials. Br J Nutr 100: 1169-1178. [Crossref]

25. Ma AG, Schouten EG, Sun YY, Yang F, Han XX, et al. (2010) Supplementation of iron alone and combined with vitamins improves haematological status, erythrocyte membrane fluidity and oxidative stress in anaemic pregnant women. $\mathrm{Br} J$ Nutr 104: 1655-1661. [Crossref]
26. Hallberg L, Brune M, Rossanderet L (1989) The role of vitamin C in iron absorption. Int J Vitam Nutr Res Suppl 30: 103-108. [Crossref]

27. Reeves PG, Demars LCS, Johnson WT, Lukaski HC (2005) Dietary Copper Deficiency Reduces Iron Absorption and Duodenal-Enterocyte Hephaestin Protein in Male and Female Rats. J Nutr 135: 92-98. [Crossref]

28. Nguyen P, Grajeda R, Melgar P, Marcinkevage J, Flores R, et al. (2012) Effect of Zinc on Efficacy of Iron Supplementation in Improving Iron and Zinc Status in Women. $J$ Nutr Metab 2012: 216179.

Copyright: (C2021 Luca Di Lullo. This is an open-access article distributed under the terms of the Creative Commons Attribution License, which permits unrestricted use, distribution, and reproduction in any medium, provided the original author and source are credited. 